\title{
A single-center analysis of clinical features of 145 tuberous sclerosis complex-associated renal angiomyolipoma cases in China
}

\section{Xu Wang}

Chinese Academy of Medical Sciences and Peking Union Medical College

\section{Yang Zhao}

Peking Union Medical College Hospital

\section{Wenda Wang}

Peking Union Medical College Hospital

\section{Zhan Wang}

Peking Union Medical College Hospital

Yushi Zhang ( $\nabla$ zhangyushi@126.com )

Peking Union Medical College Hospital

\section{Research}

Keywords: Tuberous sclerosis, Kidney, Renal angiomyolipoma, Clinical features

Posted Date: March 5th, 2020

DOl: https://doi.org/10.21203/rs.3.rs-16208/v1

License: (c) (i) This work is licensed under a Creative Commons Attribution 4.0 International License. Read Full License 


\section{Abstract}

Background: Tuberous sclerosis complex (TSC) is a rare autosomal dominant genetic disease with multiple organ system involvement. Renal angiomyolipoma (RAML) is a leading cause of death in TSCadult patients. The aim of the study was to investigate the clinical features of tuberous sclerosisassociated renal angiomyolipoma among Chinese population so that clinicians can make better clinical diagnosis.

Methods: Retrospective review of clinical data of 145 patients with tuberous sclerosis-associated renal angiomyolipoma treated in the Department of Urology, Peking Union Medical College Hospital from January 2014 to January 2019. Analysis of age and gender distribution, tumor stage, and combined clinical manifestations. All analyses used a significance level of 0.05 and were presented in SPSS23.0 software.

Results: A total of 145 patients were enrolled. There were 51 males and 94 females. The male to female ratio was 1:1.84, with mean age of $30.50 \pm 9.79$ years (range 7-58 years). 92 cases were mainly distributed in 21-40 age group, accounting for $63.45 \%$. Among all 6 age groups, 21-30 age group contained the largest number of patients(48 case $₫ 33.10 \%) .86$ (59.31\%) renal angiomyolipoma cases were classified stage 6; 19 cases had a history of tumor rupture and hemorrhage, including 7 selective arterial embolization, 8 partial nephrectomy and 4 nephrectomy. Subependymal nodules (104/122cases, $85.24 \%$ ), angiofibromas / fibrous cephalic plaque (121 cases, $83.44 \%$ ), hypomelanotic macules (89 cases, $61.39 \%$ ), shagreen patch (65 cases, $44.83 \%$ ) and ungual fibromas (62 cases, $42.07 \%$ ) were the main combined clinical manifestation. 91.30\% (42/46) lymphangioleiomyomatosis cases were female.

Conclusion: Patients with TSC-RAML were mainly young and middle-aged females with giant Angiomyolipoma. Most tumor were ranged in stage 5 and 6 . Nervous system characteristics (subependymal nodules), dermatological lesions (angiofibromas or fibrous cephalic plaque, hypomelanotic macules, shagreen patch and ungual fibromas) were common combined clinical manifestations. Lymphangioleiomyomatosis showed an obvious difference in gender distribution

\section{Background}

Tuberous sclerosis complex (TSC) is an autosomal dominant genetic disease $\mathrm{e}^{[1]}$. The pathogenesis is the mutation of TSC1 or TSC2 gene, resulting in excessive activation of the mammalian target of rapamycin(mTOR) pathway, which causes disorders of cell

growth, proliferation, and angiogenesis. The target organ of TSC includes the nervous system ${ }^{[2]}$, skin ${ }^{[3]}$, kidney $^{[4]}$, heart ${ }^{[5]}$, lung ${ }^{[6]}$, liver ${ }^{[7]}$ and almost every organ. As a rare disease with an incidence of $1 / 5800^{[8]}$, few major cases report the clinical characteristics of TSC at home and abroad. .In order to improve the understanding of this disease, this article reviews and analyzes retrospectively clinical characteristics of 145 patients with tuberous sclerosis complex-associated renal angiomyolipoma (TSC-RAML) diagnosed in Peking Union Medical College Hospital from January 2014 to January 2019. 


\section{Methods}

\section{Patient}

From January 2014 to January 2019, 145 patients with TSC-RAML diagnosed in Department of Urology of Peking Union Medical College Hospital were enrolled. The clinical featuresimaging of CT scan of head, chest and abdomen, ophthalmoscope and ultrasound results were retrospectively analyzed.

\section{Diagnostic criteria}

Clinical diagnosis according to criteria of 2012 International Tuberous Sclerosis Complex Consensus Conference ${ }^{[9]} \llbracket$ Table $1 \otimes .11$ major features and 6 minor features

were adopted.

\section{RAML Imaging Clinical Classification Standard}

The size, number, and kidney morphology of RAML were evaluated by MRI or CT, as shown in Table $2^{[10]}$.

\section{Statistical Analysis}

Data were expressed as the mean \pm standard deviation $(M \pm S D)$ or $n(\%)$. All statistical analyses were performed with IBM SPSS Statistics 23. Statistical significance was determined by Chi-square test or unpaired Student's t-test in cases of standardized expression data. $\mathrm{P}<0.05$ was considered statistically significant.

Table 1 Clinical diagnostic criteria 
Major features

1. Hypomelanotic macules ( $\square 3$, at least 5-mm diameter)

2. Angiofibromas (3) or fibrous cephalic plaque

3. Ungual fibromas ( $(2)$

4. Shagreen patch

5. Multiple retinal hamartomas

6. Cortical dysplasias*

7. Subependymal nodules (SEN)

8. Subependymal giant cell astrocytoma (SEGA)

9. Cardiac rhabdomyoma

10. Lymphangioleiomyomatosis (LAM) ${ }^{\Delta}$

11. Angiomyolipomas ( $\square 2)^{\Delta}$

Minor features

1. "Confetti" skin lesions

2. Dental enamel pits $(>3)$

3. Intraoral fibromas $(>2)$

4. Retinal achromic patch

5. Multiple renal cysts

6. Nonrenal hamartomas

Definite diagnosis: Two major features or one major feature with $\geq 2$ minor features

Possible diagnosis: Either one major feature or $\geq 2$ minor features

* Includes tubers and cerebral white matter radial migration lines.

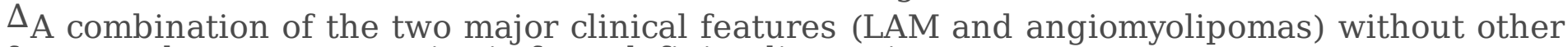
features does not meet criteria for a definite diagnosis.

Table 2 Renal angiomyolipoma staging criteria

\begin{tabular}{cccc}
\hline Stage & $\begin{array}{c}\text { Number of } \\
\text { angiomyolipomata }\end{array}$ & size & Kidney anatomy \\
\hline 0 & None & None & Normal \\
1 & $\leq 5$ & $1-3.5 \mathrm{~cm}$ & Normal \\
2 & $\square 5$ & $1-3.5 \mathrm{~cm}$ & Normal \\
3 & $\leq 5$ & At least $1 \geq 3.5 \mathrm{~cm}$ & Kidney intact \\
4 & $\square 5$ & $1-4 \geq 3.5 \mathrm{~cm}$ & Kidney intact \\
5 & $\square 5$ & 5 or more $\geq 3.5 \mathrm{~cm}$ & Kidney recognizable \\
6 & $\square 5$ & At least $1 \geq 5.0 \mathrm{~cm}$ & Kidney not recognizable \\
\hline
\end{tabular}

\section{Results}

\section{Gender and age distribution}

Our study included 51 men and 94 women (male to female ratio 1:1.84), with mean age of $30.50 \pm 9.79$ years old (range 7-58 years). $p$ value $0.153 \varangle 0.05$. The two largest number of patients are in 21-30y group (48 cases, $33.10 \%$ ) and $31-40 y$ group ( 41 cases, $28.28 \%$ ), followed by $41-50 y$ group ( 24 cases, $16.55 \%$ ) and $11-20 y$ group ( 21 cases, $14.48 \%$ ). Only $5.52 \%$ were under 10 years old ( 4 cases, $2.76 \%$ ) and over 50 years old (4 cases, $2.76 \%)$, Figure 1.

\section{RAML clinical stage}

The clinical stage of TSC-RAML is shown in Table 3. Among the 145 patients, 108 cases, $71.96 \%$ were at or above stage 5 with unrecognizable kidneys, of which 86 cases were at stage 6 (Figure 2). 19 cases had a history of tumor rupture and hemorrhage, including 3 cases in stage 2, 2 cases in stage 4, 2 cases in stage 5 and 12 cases in stage 6 , respectively. 
Table 3. TSC-RAML clinical stage

\begin{tabular}{ccc}
\hline Stage & Number & hemorrhage \\
& & \\
\hline 1 & 2 & 0 \\
2 & 13 & 3 \\
3 & 6 & 0 \\
4 & 16 & 2 \\
5 & 22 & 2 \\
6 & 86 & 12 \\
\hline & 145 & 19 \\
\hline
\end{tabular}

\section{TSC-RAML clinical characteristics}

Characteristics of 145 TSC-RAML cases were shown in Table 4 . Subependymal nodules was the most common features with a total of 104 in 122 cases (85.24\%); facial angiofibromas or fibrous cephalic plaque (121 cases, $83.44 \%$ ) and hypomelanotic macules (89 cases, $61.39 \%$ ) were the most common skin lesions; Ungual fibromas, Shagreen patch, and cortical dysplasia were roughly equal in distribution

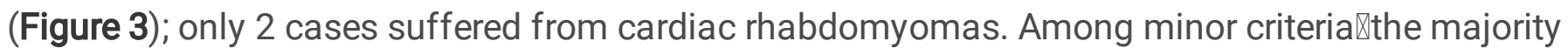
manifestation was dental enamel pits (112 cases, $77.24 \%$ ). In terms of gender distribution, $91.30 \%$ (42/46) LAM patients were female, and the proportion was significantly higher than that in other groups, $p$ value $\mathbb{0 0} 05$.

Table 4. Clinical characteristics of patients with TSC-RAML 


\begin{tabular}{lcccc}
\hline & Number & Male & Female & $P$ Value \\
& 145 & 51 & 94 & \\
\hline epilepsy & $24 / 145$ & $10 / 51$ & $14 / 94$ & 0.466 \\
\hline Major criteria & & & & \\
\hline Hypomelanotic macules $(\geq 3)$ & $89 / 145 \square 61.39 \% \square$ & 33 & 56 & 0.545 \\
Angiofibromas ( $\geq 3)$ or fibrous cephalic & $121 / 145 \square 83.44 \% \square$ & 42 & 79 & 0.794 \\
plaque & & & & \\
Ungual fibromas $(\geq 2)$ & $62 / 145 \square 42.07 \% \square$ & 17 & 45 & 0.091 \\
Shagreen patch & $65 / 145 \square 44.83 \% \square$ & 19 & 46 & 0.177 \\
Multiple retinal hamartomas & $5 / 53 \square 9.43 \% \square$ & 2 & 3 & 0.765 \\
Cortical dysplasias & $47 / 122 \square 38.52 \% \square$ & 12 & 35 & 0.446 \\
Subependymal nodules & $104 / 122 \square 85.24 \% \square$ & 28 & 76 & 0.132 \\
SEGA & $13 / 122 \square 10.65 \% \square$ & 5 & 8 & 0.454 \\
Cardiac rhabdomyoma & $2 / 25 \square 8.00 \% \square$ & 1 & 1 & 0.667 \\
LAM & $46 / 115 \square 38.98 \% \square$ & 4 & 42 & $\square 0.05$ \\
Renal AML & $145 \square 100 \% \square$ & 51 & 94 & - \\
\hline Minor criteria & & & & \\
\hline Dental enamel pits & $112 / 145 \square 77.24 \% \square$ & 28 & 83 & \\
Intraoral fibromas & $26 / 145 \square 24.30 \% \square$ & 19 & 7 & \\
Nonrenal hamartomas & $26 / 145 \square 17.93 \% \square$ & 9 & 17 & \\
Retinal achromatic patch & $8 / 53 \square 15.09 \% \square$ & 4 & 4 & \\
Confetti skin lesions & $9 / 145 \square 6.54 \% \square$ & 4 & 5 & \\
Multiple renal cysts & $17 / 145 \square 11.72 \% \square$ & 5 & 12 & \\
\hline
\end{tabular}

\section{Discussion}

Tuberous sclerosis complex was first reported by Bourneville in 1880 , so it is also known as Bourneville disease, a clinically rare autosomal dominant genetic disease, often involving multiple organ systems ${ }^{[1]}$. In the 1990s, Fryer ${ }^{[11]}$ and Kandt ${ }^{[12]}$ respectively found two disease-causing genes and named them TSC1 and TSC2. It has been shown that TSC1 or TSC2 mutations can abnormally activate the mammalian target of rapamycin (mTOR) and cause tuberous sclerosis complex ${ }^{[13]}$.

\section{Epidemiology}

An epidemiological survey in the UK showed a frequency of $1 / 12000$ to $1 / 14000$ under the age of ten $^{[14]}$. Osborne et al. claimed a birth incidence was about $1 / 5800$ by improving methods of ascertainment ${ }^{[8]}$. The age-dependent expression of clinical manifestations was disclosed by Curatolo ${ }^{[15]}$.

\section{Clinical characteristics}


Of the 145 patients with TSC-RAML in this study based on the clinical diagnostic criteria proposed by 2012 International Tuberous Sclerosis Complex Consensus Conference, male to female ratio 1:1.84, $p$ value $0.153 \otimes 0.05$ (Student's t-test), showing no statistical significance in gender and age distribution. As the most two common features, 121 cases (83.44\%) had angiofibromas or fibrous cephalic plaque and 89 cases $(61.39 \%)$ had hypomelanotic macules. In addition, 130 patients had at least one skin criteria including hypomelanotic macules, angiofibromas or fibrous cephalic plaque, shagreen patch, ungual fibromas or confetti skin lesions, accounting for $89.66 \%$. Another clinical data of 112 cases of TSC-RAML showed that $95.5 \%(107 / 112)$ had at least one of the above-mentioned skin lesions, which is basically consistent with our study results ${ }^{[16]}$. Subependymal nodules were the most common neurological features (104 out of $122,85.24 \%$ ), followed by cortical dysplasias (47 cases, $38.52 \%$ ). Among 24 patients with a history of epilepsy, subependymal nodules or (and) cortical dysplasias were detected at least. Only 2 cases were diagnosed with cardiac rhabdomyomas, which may be associated with development and outcome of the disease. In a multicenter and prospective studies enrolled 130 infants with definite TSC, cardiac rhabdomyomas was the most common initial feature, accounting for about $59 \%$. Moreover, up to $82 \%$ were detected with cardiac rhabdomyomas and prevalence increased with months before 1 year $\mathrm{old}^{[5]}$, then the prevalence decreased significantly after the age of five. Generally, lesions regress spontaneously over time and complete during childhood ${ }^{[15]}$. In our study, 38.98\% (46 in 115 cases) were TSC-LAM patients, of which women accounted for $91.30 \%$ (42/46), $p$ value $₫ 0.05$ (Chi-square test), showing significant differences in gender distribution, which was also the only statistically significant difference among all the major criteria. Lymphangioleiomyomatosis (LAM) is a rare, neoplastic disease that occurs mainly in women ${ }^{[17]}$. Most patients have clinically progressive dyspnea and repeated pneumothorax. The chest high-resolution CT mainly manifests diffused thin-wall cystic changes in the lungs ${ }^{[9]}$. There are two types of LAM, sporadic and TSC-LAM, which are caused by mutation in TSC gene. TSC mutation defects tuberin-hamartin protein complex, activates the mTOR pathway and promotes the abnormal proliferation of LAM cells ${ }^{[18]}$. In women with TSC, the prevalence of LAM ranges from $26 \%$ to $38 \%{ }^{[6]}[$ A single-center, 12-year retrospective clinical study showed that LAM was an age-dependent disease with an increasing risk by about $8 \%$. The prevalence of LAM was about $27 \%$ among female TSC patients $₫ 21 \mathrm{y}$, and $80 \%$ in those $\varangle 40 \mathrm{y}[19]$ This phenomenon may be related to the expression of estrogen and progesterone receptors in LAM cells. Clinical observations show that LAM seems to progress when estrogen levels are elevated (such as during pregnant period or taking exogenous estrogen). Ovariectomy and aromatase inhibitor decreased MMP-2 activity and expression of related markers in LAM-like tumors of uterine-specific Tsc2-null mice. Further research indicates that estrogen is likely to promote the survival and metastasis of Tsc2-null Cells through ERK and AKT pathway ${ }^{[20,21]}[$

As an international disease registry aimed to address knowledge of TSC, TOSCA (Tuberous sclerosis registry to increase disease Awareness) enrolled 2,093 patients with TSC, involving 171 research centers in 31 countries, 1009 males, 1084 females, male to female ratio $1: 1.07$, age distribution 0-70 years, average age 13 years $^{[22]}$. According to the renal manifestation in TOSCA, 47.2\% (987 cases) were diagnosed renal angiomyolipomas with male to female ratio $1: 1.35$, of which $34.8 \%$ had lesions $>3 \mathrm{~cm}$ 
and $22.8 \%$ was reported multiple renal cysts. The proportion $(89.66 \%, 130$ cases) of TSC-RAML in our study ranged stage 3 or above was significantly higher, while only $17 \otimes 11.72 \% \bigotimes$ multiple renal cysts cases. In addition, the proportion of epilepsy and cardiac rhabdomyoma in TOSCA was obviously higher than those in our study ( $83.5 \%$ vs $16.56 \% ; 34.3 \%$ vs $8.00 \%$ ). Noticeably, compared with the adults as main subjects of this study (the average age $30.50 \mathrm{y}$, the main age distribution $21-40 \mathrm{y}, 63.45 \%$ ), 63.3\% TOSCA patients were $<18 y$, and the proportion of children was as high as $57 \%$, which may account for these differences. And this study mainly analyzed the clinical characteristics of TSC-RAML, which may be another reasons for the difference in statistics.Similar to the results in TOSCA, facial angiofibromas and hypomelanotic macules were the two most common dermatological manifestations. Subependymal nodules were still one of the most common neurological manifestations.

\section{Treatment}

Compared with sporadic AML, TSC-RAML is more onset in infancy and more common in female patients. It often presents as a bilateral, multiple, large tumor that grows faster and increases the risk of spontaneous rupture and hemorrhage ${ }^{[23]}$. Studies have further shown that patients with TSC2 gene mutations have more severe kidney destruction and a higher risk of ruptured bleeding ${ }^{[24]}$. Renal complications have also become an important cause of death in patients with TSC ${ }^{[25]}$. Therefore, reasonable and correct treatment is particularly important. Selective arterial embolization and partial nephrectomy as important treatment methods for TSC-RAML have achieved satisfactory clinical results ${ }^{[26]}$. A clinical study involving 7 cases of TSC-RAML selective renal artery embolization showed that embolization was safe and effective, and had a small effect on renal function ${ }^{[27]}$. In addition, partial nephrectomy can maximize the retention of nephrons for complicated RAML ${ }^{[28]}$. In addition to surgery, Novartis's Afinitor (everolimus, an mTOR inhibitor) is currently the only FDA-approved drug for TSC-RAML that do not require immediate surgery. In a multicenter, randomized, double-blind, placebo-controlled phase III clinical trial conducted by Bissler et al, a total of 118 patients were enrolled, of which 79 were in everolimus group $(10 \mathrm{mg} /$ day, with an average treatment time of 38 weeks), 39 patients were in placebo control group (mean 34 weeks). The response rate ( $50 \%$ reduction in tumor volume) was $42 \%$ (33/79) vs $0 \%$ in the placebo group ${ }^{[16]}$. During the extension of the trial, the response rate increased to $54 \%$ with everolimus median treatment for 28.9 months ${ }^{[29]}$. A single-center, non-randomized, open-label phase II clinical trial conducted 15 cases of TSC-RAML in China demonstrated that everolimus was well tolerated and effective in Chinese patients with TSC-RAML ${ }^{[30]}$.

\section{Limitation}

Our study was a retrospective observational study of TSC-RAML based on a single center statistics. We provided the largest cases in China, however, some patients were unable to complete all TSC diagnostic criteria examinations due to economic factors or regional medical conditions. In addition, no follow-up data were available in this study because patients were lost to follow-up or the follow-up period was short. Therefore, the above content needs to be improved in the future. Furthermore, subjects of this study 
were mainly adults with fewer children. Children cases should be collected as much as possible to obtain more complete clinical characteristics of TSC patients in future studies.

\section{Conclusion}

This study retrospectively analyzed the clinical manifestations of 145 cases of TSC-RAML. As the first and largest sample report of TSC in China, it is served as reference for summarizing the characteristics of TSC-RAML in China.

\section{Abbreviations}

TSC: Tuberous sclerosis complex; mTOR: mammalian target of rapamycin; CT: Computed tomography; MRI: Magnetic resonance imaging; RAML: Renal angiomyolipoma; SEN: Subependymal nodules; SEGA: Subependymal giant cell astrocytomas.

\section{Declarations}

\section{Ethics approval and consent to participate}

Not applicable.

\section{Consent for publication}

Not applicable as no private information was disclosed.

\section{Availability of data and materials}

Data generated in this study are not publicly available. Only summary have been provided in the manuscript.

\section{Competing interests}

The authors declared that they had no competing interests.

\section{Funding}

The research was supported by the National Natural Science Foundation of China (81670611)

\section{Authors' contributions}

YSZ designed the study. XW and WDW acquired the data. XW, YZ and ZW analyzed the data. XW prepared the first draft. $Y S Z, Y Z$ and $Z W$ reviewed critically and contributed to the final revision. All authors read and approved the final manuscript. 
We thank the personnel at the department of Urology, Peking Union Medical College Hospital for their support.

\section{Authors details}

${ }^{1}$ Department of Urology, Peking Union Medical College Hospital, Chinese Academy of Medical Sciences and Peking Union Medical College, 1 Shuaifuyuan Road, Beijing 100730, China.

\section{References}

[1] Henske E P, Jóźwiak S, Kingswood J C, et al. Tuberous sclerosis complex [J]. Nature Reviews Disease Primers, 2016, 2(16035.

[2] Curatolo P, Moavero R, de Vries P J. Neurological and neuropsychiatric aspects of tuberous sclerosis complex [J]. The Lancet Neurology, 2015, 14(7): 733-745.

[3] Ebrahimi-Fakhari D, Meyer S, Vogt T, et al. Dermatological manifestations of tuberous sclerosis complex (TSC) [J]. J Dtsch Dermatol Ges, 2017, 15(7): 695-700.

[4] Samuels J A. Treatment of Renal Angiomyolipoma and Other Hamartomas in Patients with Tuberous Sclerosis Complex [J]. Clin J Am Soc Nephrol, 2017, 12(7): 1196-1202.

[5] Davis P E, Filip-Dhima R, Sideridis G, et al. Presentation and Diagnosis of Tuberous Sclerosis Complex in Infants [J]. Pediatrics, 2017, 140(6):

[6] Taveira-DaSilva A M, Moss J. Clinical features, epidemiology, and therapy of lymphangioleiomyomatosis [J]. Clin Epidemiol, 2015, 7(249-257.

[7] Jozwiak S, Sadowski K, Borkowska J, et al. Liver Angiomyolipomas in Tuberous Sclerosis ComplexTheir Incidence and Course [J]. Pediatr Neurol, 2018, 78(20-26.

[8] Osborne J P, Fryer A, Webb D. Epidemiology of tuberous sclerosis [J]. Ann N Y Acad Sci, 1991, 615(125127.

[9] Northrup H, Krueger D A. Tuberous sclerosis complex diagnostic criteria update: recommendations of the 2012 International Tuberous Sclerosis Complex Consensus Conference [J]. Pediatr Neurol, 2013, 49(4): 243-254.

[10] Vekeman F, Magestro $M$, Karner $P$, et al. Kidney involvement in tuberous sclerosis complex: the impact on healthcare resource use and costs [J]. J Med Econ, 2015, 18(12): 1060-1070.

[11] Fryer A E, Chalmers A, Connor J M, et al. Evidence that the gene for tuberous sclerosis is on chromosome 9 [J]. Lancet, 1987, 1(8534): 659-661. 
[12] Kandt R S, Haines J L, Smith M, et al. Linkage of an important gene locus for tuberous sclerosis to a chromosome 16 marker for polycystic kidney disease [J]. Nat Genet, 1992, 2(1): 37-41.

[13] Martin K R, Zhou W, Bowman M J, et al. The genomic landscape of tuberous sclerosis complex [J]. Nat Commun, 2017, 8(15816.

[14] O'Callaghan F J, Shiell A W, Osborne J P, et al. Prevalence of tuberous sclerosis estimated by capturerecapture analysis [J]. Lancet, 1998, 351(9114): 1490.

[15] Curatolo P, Bombardieri R, Jozwiak S. Tuberous sclerosis [J]. Lancet, 2008, 372(9639): 657-668.

[16] Bissler J J, Kingswood J C, Radzikowska E, et al. Everolimus long-term use in patients with tuberous sclerosis complex: Four-year update of the EXIST-2 study. [J]. PloS one, 2017, 12(8): e0180939.

[17] McCormack F X, Gupta N, Finlay G R, et al. Official American Thoracic Society/Japanese Respiratory Society Clinical Practice Guidelines: Lymphangioleiomyomatosis Diagnosis and Management [J]. American journal of respiratory and critical care medicine, 2016, 194(6): 748-761.

[18] Gupta N, Vassallo R, Wikenheiser-Brokamp K A, et al. Diffuse Cystic Lung Disease. Part I [J]. Am J Respir Crit Care Med, 2015, 191(12): 1354-1366.

[19] Cudzilo C J, Szczesniak R D, Brody A S, et al. Lymphangioleiomyomatosis screening in women with tuberous sclerosis [J]. Chest, 2013, 144(2): 578-585.

[20] Prizant H, Hammes S R. Minireview: Lymphangioleiomyomatosis (LAM): The "Other" SteroidSensitive Cancer [J]. Endocrinology, 2016, 157(9): 3374-3383.

[21] Yu J, Henske E P. mTOR activation, lymphangiogenesis, and estrogen-mediated cell survival: the "perfect storm" of pro-metastatic factors in LAM pathogenesis [J]. Lymphat Res Biol, 2010, 8(1): 43-49.

[22] Kingswood J C, d'Augeres G B, Belousova E, et al. Tuberous Sclerosis registry to increase disease Awareness (TOSCA) - baseline data on 2093 patients [J]. Orphanet J Rare Dis, 2017, 12(1): 2.

[23] Rabenou R A, Charles H W. Differentiation of Sporadic Versus Tuberous Sclerosis ComplexAssociated Angiomyolipoma [J]. AJR Am J Roentgenol, 2015, 205(2): 292-301.

[24] Cai Y, Li H, Zhang Y. Assessment of Tuberous Sclerosis Complex Associated With Renal Lesions by Targeted Next-generation Sequencing in Mainland China [J]. Urology, 2017, 101(170.e171-170.e177.

[25] Amin S, Lux A, Calder N, et al. Causes of mortality in individuals with tuberous sclerosis complex [J]. Dev Med Child Neurol, 2017, 59(6): 612-617.

[26] Flum A S, Hamoui N, Said M A, et al. Update on the Diagnosis and Management of Renal Angiomyolipoma [J]. J Urol, 2016, 195(4 Pt 1): 834-846. 
[27] CAI Yi, LI Han-zhong, ZHANG Yu-shi. Clinical Analysis of Selective Arterial Embolization in Treatment of Renal Angiomyolipoma 7 Patients with Tuberous Sclerosis Complex [J]. Clin Misdiagn Misther. 2016, 29(10): $19-21$.

[28] FAN Hua, LI Han-zhong,JI Zhi-gang, et al. Surgical Treatment for Complex Renal Angiomyolipoma [J]. Med J Peking Union Med Coll Hosp 2018, 9(04): 346-351.

[29] Bissler J J, Kingswood J C, Radzikowska E, et al. Everolimus for renal angiomyolipoma in patients with tuberous sclerosis complex or sporadic lymphangioleiomyomatosis: extension of a randomized controlled trial [J]. Nephrol Dial Transplant, 2016, 31(1): 111-119.

[30] Cai Y, Li H, Zhang Y. MP03-06 PRELIMINARY ANALYSIS THE EFFICACY AND SAFETY OF EVEROLIMUS FOR RENAL ANGIOMYOLIPOMA ASSOCIATED TUBEROUS SCLEROSIS IN CHINESE PATIENTS: A SINGLE-CENTRE, SINGLE-ARM, PHASE II STUDY [J]. The Journal of Urology, 2016, 195(4, Supplement): e21.

\section{Figures}

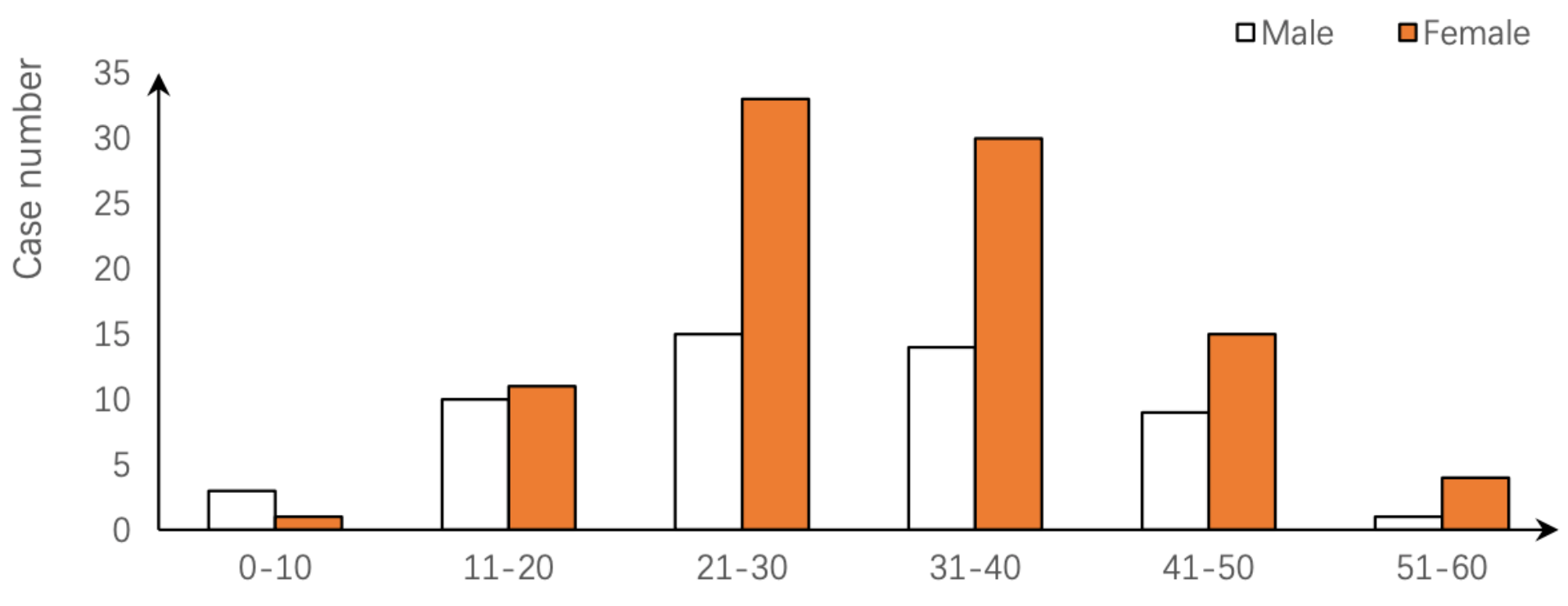

Age group

\section{Figure 1}

Gender and age distribution of TSC 

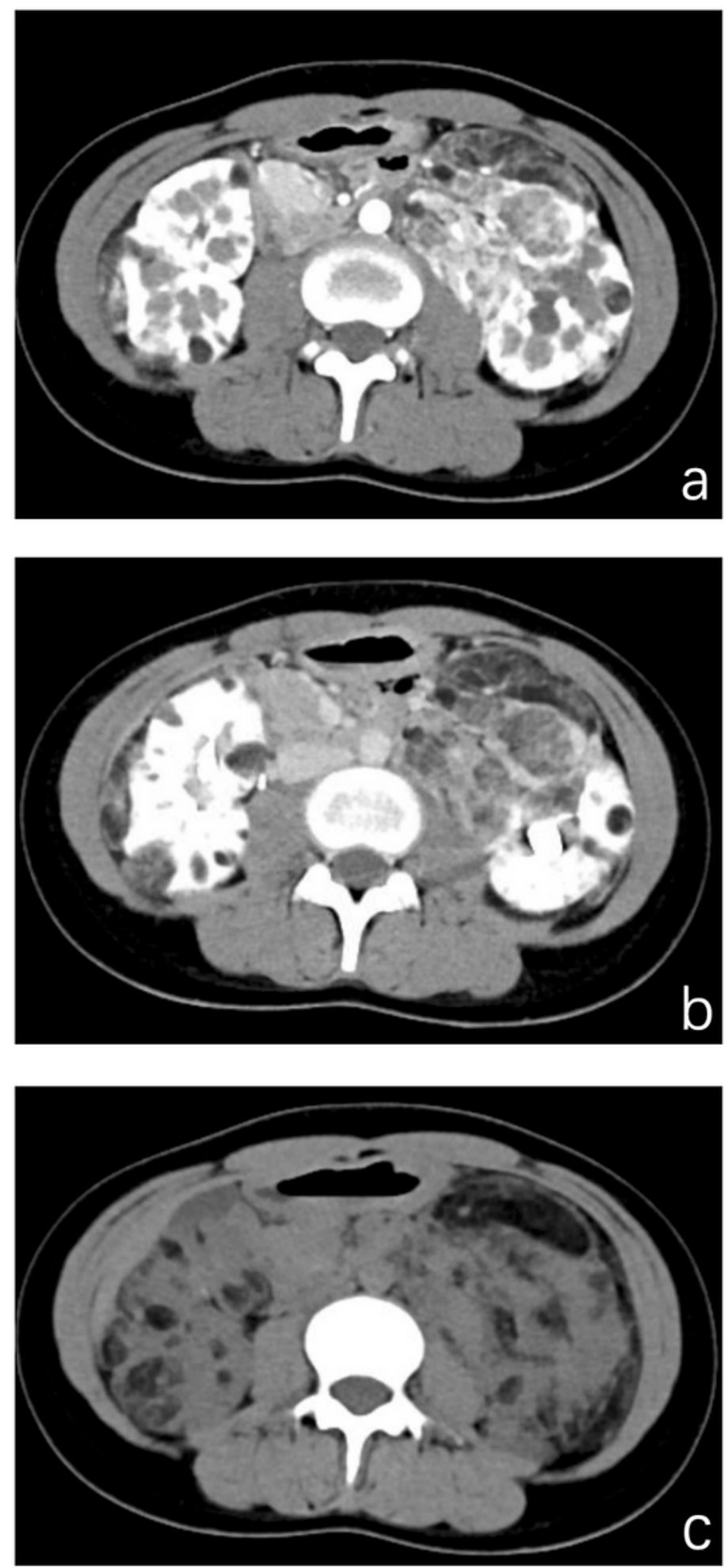

Figure 2

TSC-RAML Common combined clinical major features 

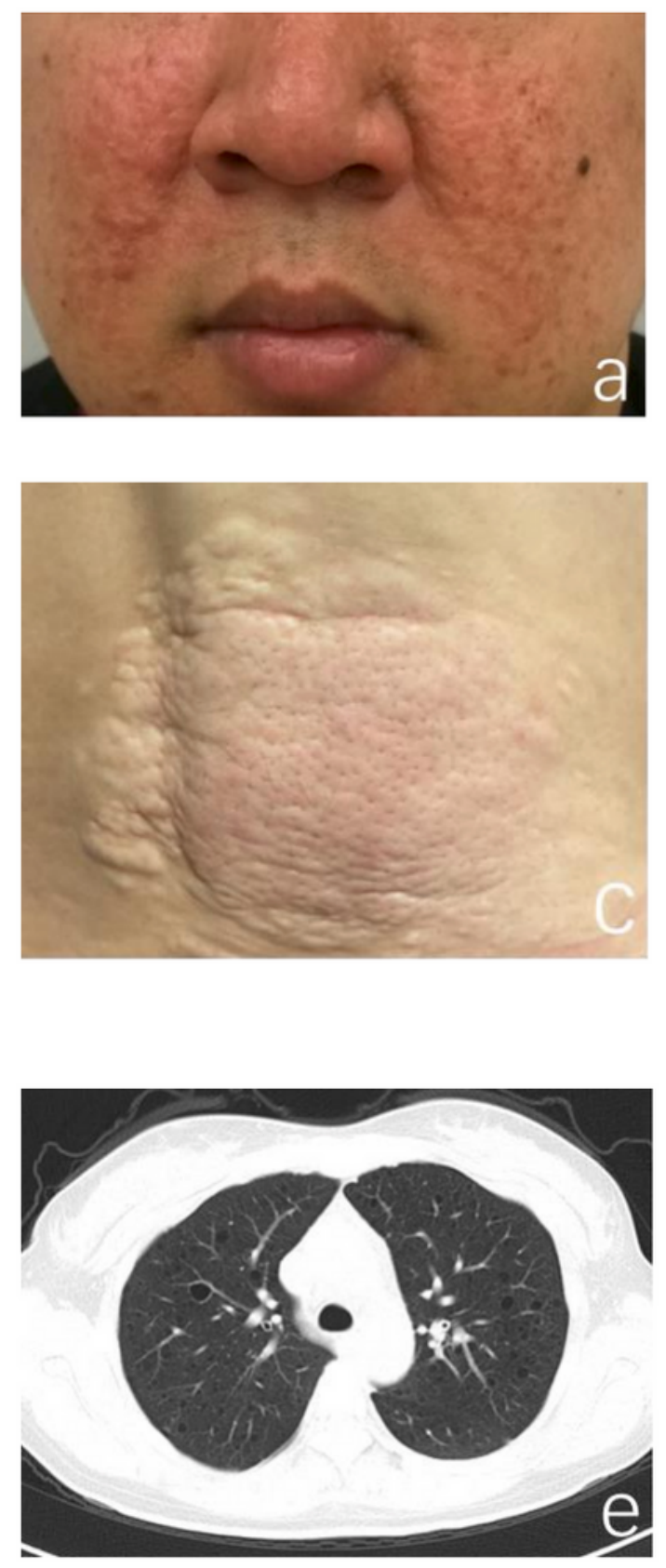
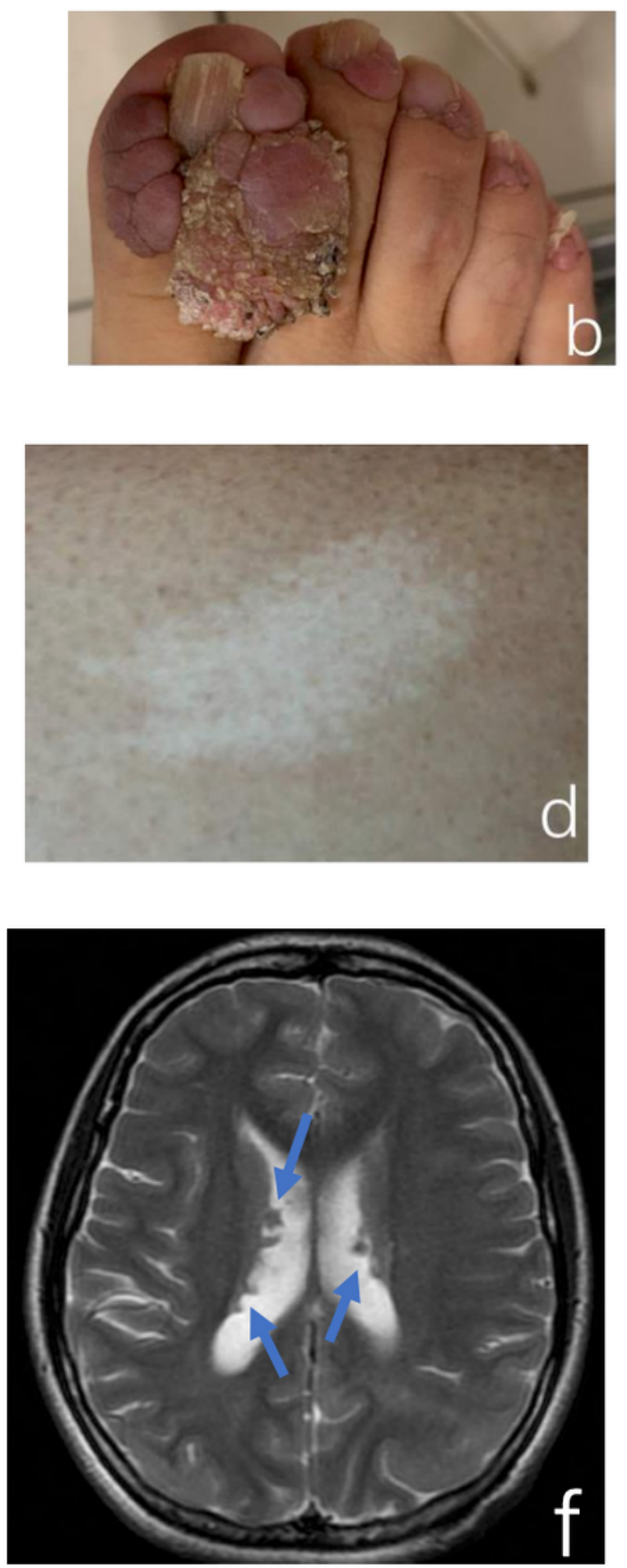

\section{Figure 3}

Subependymal nodules was the most common features with a total of 104 in 122 cases (85.24\%); facial angiofibromas or fibrous cephalic plaque (121 cases, $83.44 \%$ ) and hypomelanotic macules (89 cases, $61.39 \%$ ) were the most common skin lesions; Ungual fibromas, Shagreen patch, and cortical dysplasia were roughly equal in distribution 